\title{
12. Image-Orthicon Spectra of Geminids in 1969
}

\author{
P. M. Millman \\ National Research Council of Canada \\ Ottawa, Ontario \\ A. F. Cook \\ Smithsonian Astrophysical Observatory \\ Cambridge, Massachusetts \\ AND \\ C. L. Hemenway \\ Albany, New York
}

State University of New York at Albany and Dudley Observatory

\begin{abstract}
The spectra of 25 meteors, recorded with an image-orthicon technique in December 1969, are studied in relation to similar records made in August of the same year. Of 19 Geminid meteors in the absolute visual magnitude range $O$ to +2 , only one showed any evidence of the forbidden line of oxygen at $5577 \AA$, while all Perseid meteors recorded in August exhibited the oxygen line, a result of the large difference in geocentric velocity between the two showers. Atoms identified in faint Geminid meteors include neutral iron, magnesium, calcium and sodium. The molecular bands of nitrogen are also observed.
\end{abstract}

$\mathrm{T}_{\mathrm{s}}^{\mathrm{n}}$ HE PROGRAM OF IMAGE-ORTHICON METEOR SPECTROSCOPY, operated at the Springhill Meteor Observatory (lat $45^{\circ} 12^{\prime} \mathrm{N}$, long. $75^{\circ} 28^{\prime} \mathrm{W}$, elev $101.5 \mathrm{~m}$ ) in conjunction with meteor radar, photographic and visual programs, was commenced in August 1969. A report on the 1969 Perseid meteors observed by the image-orthicon technique was made by Millman, Cook, and Hemenway (1371). This present paper gives some preliminary results from observations of the Geminid meteor shower, made in December 1969. The observing equipment used has been described previously by Hemenway, Swider and Bowman (1971).

\section{OBSERVATIONAL DATA}

The combined observational program was carried out at Springhill on two nights, December
$12 / 13$ and $13 / 14,1969$. In $7^{\mathrm{h}} 41^{\mathrm{m}}$ observing time with the image-orthicon equipment some 41 meteors were recorded. Of these records 16 were unsuitable for detailed study, showing only one feature or being too faint for analysis. The remaining 25 orthicon spectra were divided into four groups on the basis of the detail shown and apparent shower affiliation.

Observational parameters for the 25 meteors studied are listed in table 1. An identifying serial number was assigned in chronological order to all 41 orthicon records and these numbers appear in the first column. The next four columns list the Universal Time of each meteor by day, hour, minute and second respectively. The type of radar echo recorded on the range-time display of the high-power ( $3 \mathrm{MW}$ ) equipment at Springhill is listed in the original terminology 
TABLe 1.-Observational Parameters for 25 Meteors, December 1969

\begin{tabular}{|c|c|c|c|c|c|c|c|c|c|}
\hline \multirow{2}{*}{$\begin{array}{c}\text { Serial } \\
\text { no. }\end{array}$} & \multirow{2}{*}{$\begin{array}{l}\text { Universal time } \\
\text { d h } \mathrm{m} \quad \mathrm{s}\end{array}$} & \multicolumn{2}{|c|}{ Radar echo } & \multicolumn{2}{|c|}{ Orthicon record } & \multicolumn{2}{|c|}{ Height } & \multirow{2}{*}{$\begin{array}{c}\text { Spectrum } \\
\text { features }\end{array}$} & \multirow{2}{*}{$\begin{array}{l}\text { Apparent } \\
\text { visual } \\
\text { magnitude }\end{array}$} \\
\hline & & type & $\begin{array}{l}\text { duration } \\
\text { (s) }\end{array}$ & $\begin{array}{c}\text { Motion } \\
\text { (frames) }\end{array}$ & $\begin{array}{c}\text { Duration } \\
\text { (frames) }\end{array}$ & $\begin{array}{c}\text { Begin } \\
(\mathrm{km})\end{array}$ & $\begin{array}{l}\text { End } \\
(\mathrm{km})\end{array}$ & & \\
\hline
\end{tabular}

Group I (Geminids)

\begin{tabular}{r|rrrr|cc|rc|cc|c|c}
13 & 13 & 09 & 55 & 10 & Ahe2 & 27 & 8 & 11 & 95 & 78 & 16 & \\
1 & 13 & 05 & 05 & 18 & E3 & 49 & 7 & 14 & 93 & 77 & 14 & 2 \\
18 & 13 & 10 & 29 & 13 & Ahe3 & 42 & 5 & $>14$ & $(95)$ & 78 & 14 & \\
3 & 13 & 05 & 19 & 01 & (F) & $(22)$ & 11 & 19 & $(95)$ & 87 & 13 & $0($ tr 1 s) \\
41 & 14 & 11 & 00 & 06 & Af & 20 & 6 & 9 & 93 & 80 & 12 & \\
6 & 13 & 06 & 00 & 10 & F & 19 & 4 & 2 & $(102)$ & 95 & 12 & $11 / 2$ \\
16 & 13 & 10 & 14 & 14 & Af & 21 & 6 & 5 & 93 & 79 & 10 & \\
37 & 14 & 10 & 24 & 45 & Af & 18 & 7 & 12 & 92 & 79 & 10 &
\end{tabular}

Group II (Geminids)

\begin{tabular}{l|llll|l}
32 & 14 & 09 & 35 & 21 & Af \\
17 & 13 & 10 & 22 & 07 & Ahe2 \\
21 & 13 & 11 & 04 & 43 & Ahf \\
29 & 14 & 09 & 26 & 11 & Ahf \\
28 & 14 & 09 & 18 & 11 & Ahf \\
34 & 14 & 09 & 55 & 07 & Ahe2
\end{tabular}

\begin{tabular}{c|r}
29 & $>5$ \\
32 & 6 \\
1.8 & 5 \\
1.3 & 4 \\
17 & 3 \\
17 & 2
\end{tabular}

\begin{tabular}{c|r}
$>7$ & 92 \\
7 & $(103)$ \\
3 & 82 \\
$(15)$ & 107 \\
4 & 90 \\
2 & 95
\end{tabular}

\begin{tabular}{l|r|}
$(77)$ & 8 \\
$(76)$ & 7 \\
73 & 6 \\
94 & 6 \\
83 & 5 \\
84 & 5 \\
\hline
\end{tabular}

Group III (Geminids)

\begin{tabular}{l|llll|c}
36 & 14 & 10 & 10 & 58 & Ahf \\
38 & 14 & 10 & 27 & 27 & Af \\
33 & 14 & 09 & 37 & 31 & Ah \\
23 & 14 & 08 & 18 & 52 & Dhbe2 \\
26 & 14 & 08 & 48 & 49 & Ahe2
\end{tabular}

\begin{tabular}{c|l}
14 & 2 \\
12 & 2 \\
0.2 & 2 \\
29 & 2 \\
13 & 4
\end{tabular}

\begin{tabular}{l|c}
2 & 93 \\
8 & 92 \\
6 & $(93)$ \\
0 & 92 \\
2 & 96
\end{tabular}

\begin{tabular}{l|l|}
84 & 4 \\
82 & 3 \\
87 & 3 \\
82 & 3 \\
91 & 2
\end{tabular}

Group IV (Non-shower)

\begin{tabular}{|c|c|c|c|c|c|c|c|c|c|c|c|c|}
\hline 9 & $\mid 13$ & 08 & 04 & 57 & - & - & 0 & (17) & - & - & a7 & 3 \\
\hline 27 & 14 & 09 & 17 & 23 & Af & 12 & 6 & $\mathbf{5}$ & 97 & 88 & 7 & \\
\hline 24 & 14 & 08 & 39 & 55 & E2 & 1.0 & $>5$ & $>5$ & 92 & (76) & $>5$ & \\
\hline 30 & 14 & 09 & 28 & 36 & F & 21 & 2 & 7 & 95 & $(90)$ & 6 & \\
\hline 8 & 13 & 06 & 07 & 27 & $\mathbf{F}$ & 14 & 2 & 0 & 90 & 87 & 2 & $11 / 2$ \\
\hline 2 & 13 & 05 & 18 & 09 & - & - & 3 & 0 & - & - & 2 & 3 \\
\hline
\end{tabular}

- Showing $5577 \AA$ of O I.

developed by McKinley and Millman (1949), followed by the maximum duration of the echo on this radar. For meteor 9 there was no radar echo and for meteors 2 and 3 the high-power radar was off for a film change. Meteor 3 was recorded on the low-power $(20 \mathrm{kw})$ equipment and the observed duration, indicated by brackets, must be multiplied by an empirical factor of 1.65 to convert to high-power duration.

The image-orthicon record frames were re- corded at a frequency of $15 / \mathrm{s}$. In columns 8 and 9 the duration of observed motion of the meteor image, and the maximum observed duration for the brightest feature in the spectrum, are recorded in units of frames. The field covered by the image orthicon was centered at an elevation of $45^{\circ}$ and due east, true azimuth $090^{\circ}$. Using the zero-order star images as calibration points the elevation and azimuth were read off for the beginning and end of each meteor trail. These 
were then combined with the radar ranges to give the tabulated heights. It should be noted that the heights given in table 1 were determined without the assistance of photographic records which were available in the case of some heights listed previously for the Perseids. Individual values of Geminid heights could have errors of 2 or $3 \mathrm{~km}$, or more in uncertain cases. Where the height is somewhat uncertain due to incompleteness of data the number is given in brackets. In the last two columns are listed the number of different spectral features observed and the visual magnitudes. It is unfortunate that there was not more of an overlap between the visual and the orthicon records.
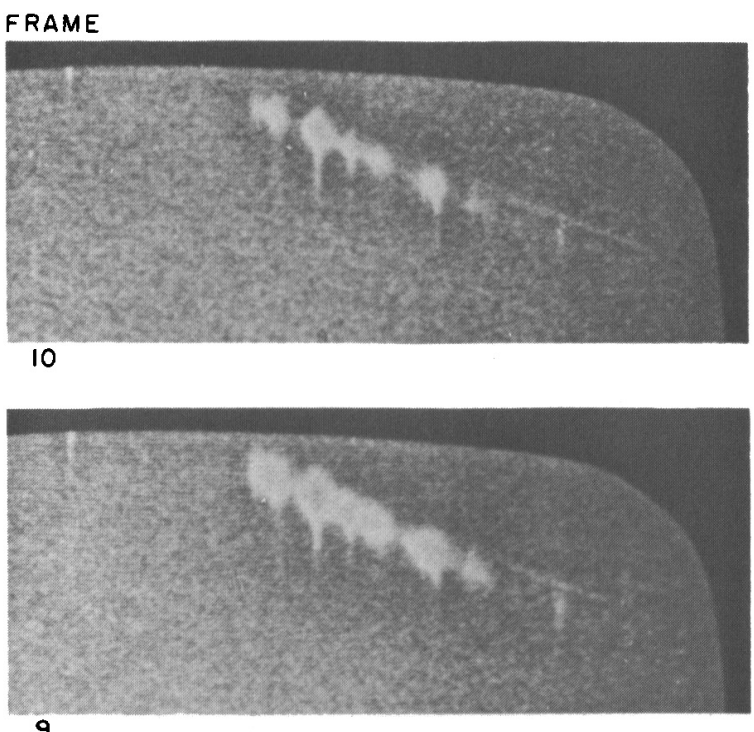

9

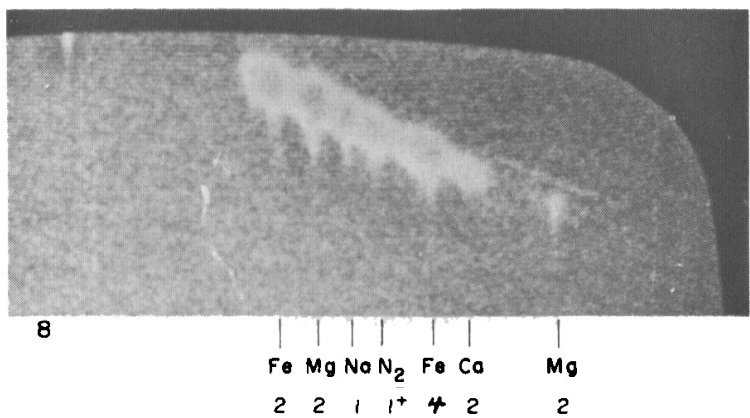

Figure 1.-Three successive frames from the record of meteor no. 1 in Group I. The apparent visual magnitude of this meteor was 2 , absolute visual magnitude +1.1 , and 14 different spectral features were measured.

\section{SPECTROSCOPIC IDENTIFICATIONS}

The study of the spectra was carried out by identifying the features in the records of Group I, and then using these identifications to extrapolate for the fainter, less-detailed spectra in the other groups. A general knowledge of the nature of Geminid meteor spectra was also available from previous photographic programs. Typical spectra from Group I are reproduced in figures 1 and 2. The definition was not good enough for more than a very approximate wavelength determination but the identity of various features could easily be followed from the strong spectra down to the weakest examples. A complete list of the features identified in all the spectra is given by wavelength in table 2 . The chief contributors to these features are listed by multiplet in the second column of the table. The last five columns give the number of times each feature was identified in the various groups. No photometry of the spectra was attempted but the intensity of each
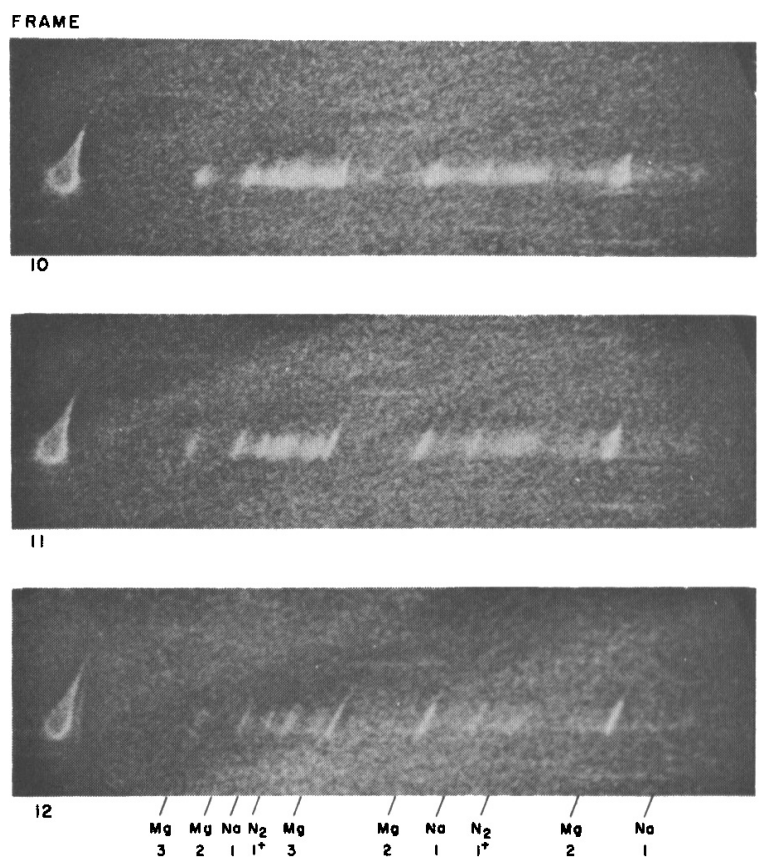

Figure 2.-Three successive frames from the record of meteor no. 3 in Group I. This meteor had a visual train of 1-s duration and the observed apparent visual magnitude was 0 , giving an absolute visual magnitude of -0.2 . Note the difference in appearance between the nitrogen bands and the magnesium lines. 
TABLE 2.-Spectroscopic Features Identified

\begin{tabular}{|c|c|c|c|c|c|c|}
\hline \multirow{2}{*}{$\begin{array}{c}\text { Approximate } \\
\text { wavelength }(\AA)\end{array}$} & \multirow{2}{*}{$\begin{array}{l}\text { Dominant contributing } \\
\text { multiplets (Moore, 1945) }\end{array}$} & \multicolumn{5}{|c|}{ Frequency of identification } \\
\hline & & Group I & Group II & Group III & Group IV & All \\
\hline 3450 & $\mathrm{Fe} I(6)$ & 3 & 0 & $\mathbf{0}$ & $\mathbf{0}$ & 3 \\
\hline 3580 & $\mathrm{Fe} I(23)(24)$ & 6 & 1 & 0 & 1 & 8 \\
\hline 3730 & Fe I (5)(21) & 8 & 3 & 0 & 3 & 14 \\
\hline 3880 & $\mathrm{Fe} I(4)(20), \mathrm{Mg} I(3)$ & 8 & 6 & 2 & $\mathbf{5}$ & 21 \\
\hline 4070 & Fe I (43) & 5 & 0 & 0 & 0 & 5 \\
\hline 4230 & $\mathrm{Fe} I(3), \mathrm{Ca} I(2)$ & 7 & 5 & $\mathbf{0}$ & 4 & 16 \\
\hline 4380 & Fe I (2) (41) & 7 & 5 & 2 & 5 & 19 \\
\hline 4700 & $\operatorname{Mg} I(11)$ & 2 & $\mathbf{0}$ & 0 & 0 & 2 \\
\hline 4900 & Fe I (318) & 3. & 0 & 0 & 0 & $\mathbf{3}$ \\
\hline 5180 & $\mathrm{Fe} I(1), \mathrm{Mg} \mathrm{I}(2)$ & 8 & 6 & 5 & 6 & 25 \\
\hline 5350 & Fe I (15) & 2 & 0 & 0 & 0 & 2 \\
\hline 5580 & O I (3F) & 0 & 1 & 0 & 1 & $\mathbf{2}$ \\
\hline 5890 & $\mathrm{NaI}(1)$ & 8 & 5 & 5 & 6 & 24 \\
\hline 6170 & $\mathrm{Ca} \mathrm{I}(3)(20)$ & 2 & 0 & 0 & 0 & 2 \\
\hline 6300 & & & & & & \\
\hline 6500$\}$ & $\mathrm{N}_{2} 1 \mathrm{st}^{+}$ & 8 & 6 & 3 & 5 & 22 \\
\hline 6700 & & & & & & \\
\hline
\end{tabular}

feature is closely correlated with the number of times it is identified.

These spectra exhibit normal characteristics for Geminid meteors. The Mg green multiplet is generally strongest, followed closely by the $\mathrm{Na}$ yellow lines. Then we have low level Fe multiplets in the blue and violet and the $\mathrm{N}_{2}$ molecular bands in the red. The image orthicon durations listed in table 1 correspond to the tube memory, except for the two cases where the $O$ I line at $5577 \AA$ was identified. These durations, indicated by brackets, are out of line with the others and represent real durations of the green-line luminosity. They correspond to the durations for the same feature found in image-orthicon Perseid spectra (Millman et al., 1971). However, in contrast to the Perseids, where all spectra studied exhibited the oxygen green line, only one Geminid spectrum, No. 29, showed this feature. There is always the possibility that this was not a Geminid meteor, even though the trail seemed to agree with the mean radiant position. The duration of motion was too short to check the shower affiliation through a measure of angular velocity.

\section{DISCUSSION}

The mean values, by group, of various observational parameters are listed in table 3 . In columns 4 and 5 the mean logs of peak amplitude are given for the head echoes $(h)$ and the long enduring echoes $(e)$, using arbitrary units. The three groups of Geminid spectra, selected by numbers of features, represent successively fainter groups of meteors. This is indicated by the successively shorter mean durations of the radar echoes, and a similar sequence for the orthicon motion durations and image durations. A good estimate of the luminosity of the meteors in the three groups is difficult because of the small number of visual records, but using the values of table 3 , and comparing with similar results in the previous study of the Perseid shower (Millman et al., 1971), we can conclude that the mean absolute visual magnitude of Group $I$ is about +0.5 , with the meteors in Groups II and III being some half to one magnitude fainter. The height of the oxygen line in Meteor 29 was omitted in calculating the mean heights listed in 
TABLE 3.-Mean Values of Observational Parameters by Group

\begin{tabular}{|c|c|c|c|c|c|c|c|c|c|}
\hline \multirow{2}{*}{ Group } & \multirow{2}{*}{$\begin{array}{c}\text { Spectrum } \\
\text { features }\end{array}$} & \multicolumn{3}{|c|}{ Radar echo } & \multirow{2}{*}{$\begin{array}{c}\text { Interval, } \\
\text { radar echo to } \\
\text { orthicon record } \\
\text { (s) }\end{array}$} & \multicolumn{2}{|c|}{ Orthicon record } & \multicolumn{2}{|c|}{ Height } \\
\hline & & $\begin{array}{l}\text { Duration } \\
\text { (s) }\end{array}$ & $\begin{array}{c}h \\
\text { ampl. } \\
(\log )\end{array}$ & $\begin{array}{c}e \\
\text { ampl. } \\
(\log )\end{array}$ & & $\begin{array}{l}\text { Motion } \\
\text { duration } \\
\text { (s) }\end{array}$ & $\begin{array}{l}\text { Image } \\
\text { duration } \\
\text { (s) }\end{array}$ & $\begin{array}{c}\text { Begin } \\
(\mathrm{km})\end{array}$ & $\begin{array}{l}\text { End } \\
(\mathrm{km})\end{array}$ \\
\hline $\mathbf{I}$ & 13 & 27 & 0.16 & 1.95 & 0.4 & 0.45 & 0.61 & 94 & 82 \\
\hline II & 6 & 9.3 & 0.12 & 1.37 & 0.9 & 0.30 & 0.28 & 91 & 82 \\
\hline III & 3 & 6.6 & 0.04 & 1.53 & 0.7 & 0.16 & 0.17 & 93 & 85 \\
\hline IV & 5 & 7.8 & - & 1.53 & 0.8 & 0.27 & 0.21 & 94 & 86 \\
\hline
\end{tabular}

table 3. The orthicon heights for the Geminid spectra average about $14 \mathrm{~km}$ lower than for the Perseid spectra, a somewhat greater differential than would have been expected on the basis of the relative geocentric velocities of the two showers, $35: 60 \mathrm{~km} / \mathrm{s}$.

In summary we see that the spectra of the shower Geminid meteors in the visual absolute magnitude range from 0 to +2 show little or no evidence of the oxygen line at $5577 \AA$ while the orthicon spectra of the faster Perseid meteors in the same luminosity class all exhibit this feature. The early continuum at the upper end of the meteor trails, observed so prominently in the Perseid spectra, seems much fainter or absent in these Geminid spectra, though there is still an indication of very faint band structure. This point requires further study.

\section{REFERENCES}

Hemenway, C. L., Swider, A., and Bowman, C., 1971. Meteor spectroscopy using an image orthicon, Can. J. Phys., 49, 1361-1364.

McKinley, D. W. R., ANd Millman, P. M., 1949. A phenomenological theory of radar echoes from meteors, Proc. Inst. Radio Eng., 37, 364-375.

Millman, P. M., Cook, A. F., and Hemenway, C. L., 1971. Spectroscopy of Perseid meteors with an image orthicon, Can. J. Phys., 49, 1365-1373.

Moore, C. E., 1945. A multiplet table of astrophysical interest, Contrib. Princeton Univ. Obs., No. 20, parts $1,2$. 